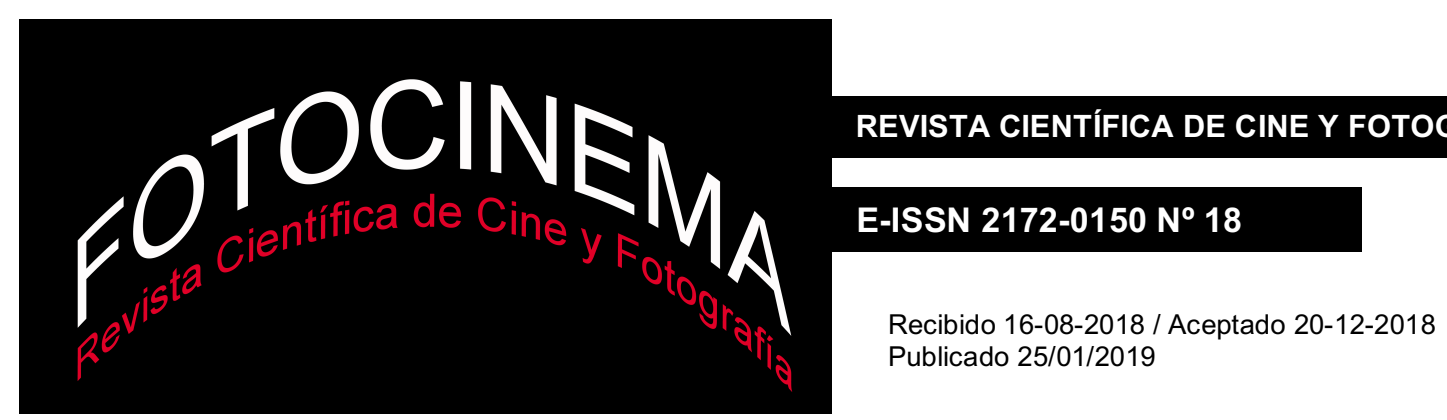

\title{
La naturaleza en la fotografía de Virxilio Viéitez
}

\author{
Nature in Virxilio Viéitez's photography
}

\author{
Miguel Cavadas Docampo \\ Universidad de Santiago de Compostela, España \\ miguel.cavadas@rai.usc.es
}

\section{Resumen:}

El presente ensayo propone una aproximación al archivo del fotógrafo rural gallego Virxilio Viéitez (1930-2008) desde la perspectiva teórica de la ecocrítica, con el fin de profundizar en el papel de la naturaleza en sus fotografías. El análisis se organiza en tres núcleos; el primero, la representación del paisaje, plantea una caracterización del paisaje unitario de la comarca en la que el fotógrafo llevó a cabo su obra, Terra de Montes (Pontevedra), e indaga en el rol que juega el humano dentro de ella. El segundo, los animales, ofrece una propuesta de clasificación para las especies que aparecen en el archivo en función de su relación con el ser humano e introduce la noción de "cambio", esencial en el tercer núcleo, la imagen del rural, que define la visión de la aldea que transmite el archivo y sus variaciones cronológicas. En la conclusión se aplica lo estudiado a la realidad actual del rural gallego con el objetivo de inspirar una respuesta del activismo ruralista al proceso de "colonización urbana" del ámbito rural que se viene evidenciando a lo largo del trabajo.

\begin{abstract}
:
The present essay suggests an approach to the archive of Galician rural photographer Virxilio Viéitez (1930-2008) from the theoretical view of ecocriticism, with the aim of delve into the role of nature in his photographs. The analysis is organized in three points; the first, representation of landscape, poses a characterization of the unit landscape of the region in which the photographer performed his work, Terra de Montes (Pontevedra), and studies the role that humans play in it. The second, animals, offers a proposal of classification for the species that appear in the archive according to their relation to human being and introduces the notion of "change", essential in the third point, the image of the rural, which defines the vision of the village the archive gives and its chronological variations. In the conclusion the previous points are brought to the current reality of rural Galicia with the objective of inspiring a response from rural activism to the process of "urban colonization" of the rural area that is demonstrated throughout the work.
\end{abstract}

Palabras clave:

Virxilio Viéitez; naturaleza; ecocrítica; paisaje; animales; rural.

Keywords:

Virxilio Viéitez; Nature; Ecocriticism; Landscape; Animals; Rural. 


\section{Introducción: Viéitez en su contexto geográfico}

Virxilio Viéitez (1930-2008) fue el fotógrafo de Soutelo de Montes. Basta esta sencilla aproximación a su figura para intuir los parámetros adecuados para el análisis de su obra. En primer lugar, lo de Viéitez era un oficio; no es necesario, en un ejercicio de voluntad academicista, rastrear vinculaciones con corrientes artísticas en sus trabajos para explicarlos; de hecho, su obra se sitúa en la periferia del campo artístico, inseparable del contexto espacial y temporal en el que fue creada. No obstante, esto no debe conllevar un enfoque reduccionista que restrinja su obra a un mero documento etnográfico. En las instantáneas de Viéitez se aprecia una consideración especial de su profesión por parte de los clientes y de él mismo, sumada a una toma de decisiones con intencionalidad estética que lo elevan a la órbita de la creación artística. En segundo lugar, el acotamiento territorial en que desarrollaba su labor implica que la trayectoria de Viéitez se basó en el proceso de configuración de un ingente archivo fotográfico que certifica el paso del tiempo en la comarca de Terra de Montes, lo que Laura Terré (2008) dio en denominar un "archivo de aldea". El archivo de aldea consta de una cantidad de imágenes muy elevada cuya razón de ser evidencia las funciones de la fotografía en el ámbito rural gallego de la segunda mitad del siglo XX. Pese a la variedad que se encuentra en el archivo Viéitez, el realismo es un trazo común a todas las entradas, por su carácter de encargo y porque el distanciamiento entre retratista y retratados es nulo, pues todos pertenecen al mismo grupo. Este aspecto es el que emprende un diálogo entre la obra de Viéitez y la de otros fotógrafos rurales gallegos, de forma singular la del muxián Ramón Caamaño, que establece multitud de paralelismos con la de Viéitez, especialmente en lo tocante a los trabajos agrarios y los animales. Caamaño incluso llega a aparecer como fotografiado en numerosas ocasiones, demostrando que la imagen que se presenta de los retratados es una autoimagen y no una heteroimagen. Incluso se podrían rastrear vinculaciones más lejanas en el eje espacial, pues el fenómeno de la fotografía rural no se limita al interior de la frontera gallega, sino que es frecuente también en otras zonas de la península, como atestigua el flujo de obras surgidas en los últimos años que pretenden iluminar por vez primera a fotógrafos que, como Viéitez, son fundamentales a la hora de construir una historia de la fotografía en España que refleje fielmente el impacto social de la imagen. Sirva como ejemplo del área manchega el trabajo de Carlos Chaparro (2014), La 
Memoria en Plata. Una historia social de la fotografía en el Campo de Montiel (1863-1940).

Volviendo a la comarca de Terra de Montes, Viéitez no es el único artista que empleó la naturaleza como elemento clave para la configuración de su obra. Aun así, sorprende el bajo número de obras artísticas que reflejan la naturaleza en una comarca en la que esta está presente hasta en su denominación. De cara a analizar la representación de Terra de Montes en las artes, el corpus que se configura es reducido y básicamente literario, compuesto de versos de Avelino Cachafeiro (1899-1972), Xosé Roxelio Otero Espasandín (1900-1987) y Manuel Blanco Rivas, los tres oriundos del lugar. También el pontevedrés Luis Amado Carballo (1901-1927) compuso dos poemas sobre el paisaje de Soutelo de Montes a raíz de una estancia en el pueblo․ Además, resultan testimonios textuales de interés notable las referencias a Cerdedo y su vegetación que se hallan en Viaxe a Galicia (1745) de Frei Martín Sarmiento (1695-1772), y el estudio A rapa das bestas de Manuel Cabada, sobre la polémica celebración homónima que se lleva a cabo cada año en Sabucedo. En el ámbito extratextual, el pintor Virxilio Blanco (1896-1948) le dedicó un ciclo de lienzos al paisaje de su tierra natal y el director de cine Chano Piñeiro (1954-1995) su primer cortometraje, Mamasunción (1984), para tratar el tema de la emigración. De entre todas estas obras, las imágenes del fotógrafo Virxilio Viéitez sobresalen por constituir el testimonio gráfico idóneo para examinar la visión de la naturaleza por parte del rural gallego y sus relaciones a lo largo de la segunda mitad del siglo pasado desde una óptica ecocrítica.

\section{Marco teórico: la ecocrítica aplicada a la fotografía}

La ecocrítica es, de manera sencilla, "el estudio de la relación entre la literatura y el medio ambiente físico" (Glotfelty, 1996, p. 54). Proviene, por tanto, de los estudios literarios, pero en virtud de su metodología, su popularidad actual en el mundo académico y su dimensión activista, puede extenderse a otras disciplinas artísticas. Si uno de los esfuerzos primordiales de la ecocrítica es "recuperar el hasta ahora descuidado género nature writing (literatura de la naturaleza)” (Glotfelty, 1996, p. 61), a la hora de tratar la modalidad de la nature photography

\footnotetext{
${ }^{1}$ Se trata de Arriero y Canto de arada, recopilados en el poemario O galo (1928).
} 
habrá que ir un paso más allá, pues tal género lleva acompañando a la fotografía desde su nacimiento. En líneas generales, las conexiones de la naturaleza con la fotografía han rendido más que sus análogas con la literatura. Esto se debe a que, antes de intereses artísticos, científicos o comerciales, la fotografía acerca espacios y tiempos distantes. No se trata, por tanto, de "recuperar" una tendencia, sino de que desempeñe "un papel fundamental a la hora de enseñarnos a valorar el mundo natural” (p. 62), como afirma Glotfelty que sería deseable de la nature writing. Según esta pauta, el enfoque ecocrítico estará presente en la obra de un fotógrafo si uno de sus objetivos es transmitir un mensaje que sea capaz de crear conciencia sobre los problemas que afectan a la naturaleza y la responsabilidad del ser humano sobre ellos. Además, esa voluntad ética deberá estar presente en el propio modo de trabajo del fotógrafo atendiendo a los materiales y técnicas que emplea. En este sentido la fotografía goza de una mayor libertad en la representación de la naturaleza que el cine, el cual, en tanto que industria cultural, depende de muchos factores externos al creador que limitan sus decisiones, en especial el espectador, como afirma Willoquet-Maricondi:

La naturaleza en las películas está socialmente construida por una serie de factores: las capacidades de la tecnología cinematográfica, los objetivos del creador, la economía de la industria del entretenimiento, el concepto de naturaleza imperante y los gustos cotejados del espectador (2010, p. 8) ${ }^{2}$.

Entre la nómina de fotógrafos ecologistas entran aquellos que plasman en su obra el conflicto entre el mundo natural y las necesidades y deseos humanos con un afán crítico, como por ejemplo el canadiense Edward Burtynsky. En el otro extremo se sitúan aquellos fotógrafos que transcriben gráficamente la tradición de la pastoral, literaria hasta que "la posterior popularización de la poesía romántica aportó el lenguaje, imaginería e incluso localizaciones para la subsiguiente generalización de la pastoral en formas culturales tan diversas" (Garrad, 2004, p. 34)3. Estos fotógrafos tienden a exhibir una visión mayestática de la naturaleza y a procurar lo bello y lo sublime, evitando aspectos críticos o

\footnotetext{
2 "Nature in films is socially constructed by a number of factors: the capabilities of the cinematic technology, the filmmakers' objectives, the economics of the entertainment industry, the prevailing concepts of nature, and the perceived tastes of viewers". La traducción que se ofrece de las citas en una lengua ajena al español es mía.

3 "The later popularisation of Romantic poetry has provided the language, imagery and even locations for the subsequent generalisation of pastoral in such diverse cultural forms".
} 
negativos. Travis Burke, Frans Lanting o George Lepp son ejemplos de esta orientación. Estas dos posturas no son antagónicas, sino que pueden aparecer combinadas incluso en los diferentes trabajos de un mismo artista. Virxilio Viéitez no se sitúa en ninguna porque la naturaleza nunca se exhibe de forma directa en su obra, es decir, no es nature photography. Sin embargo, esta ausencia también es significativa, ya que resulta igual de interesante descifrar el papel que tiene la naturaleza como marco y el nexo que establece con el sujeto humano retratado, que es siempre el elemento central en la fotografía de Viéitez. Teniendo presentes estos parámetros, se puede proceder a analizar el archivo Viéitez desde una perspectiva ecocrítica orientada en tres ejes: la representación del paisaje, la presencia de los animales y la visión del rural.

\section{Análisis ecocrítico del archivo Viéitez}

\section{1. El paisaje}

Para caracterizar el paisaje que aparece en las fotografías de Viéitez conviene recurrir en primer lugar al topónimo, Terra de Montes. Sin embargo, el concepto "monte" comporta escollos a la hora de contraponerlo a "montaña" o "sierra", que son dos de las composiciones que Ramón Otero Pedrayo (1955) propone en su clasificación del paisaje gallego, en la que el término "monte" como tal no se lista. El autor orensano deja clara la diferencia entre "montaña" y "sierra" y admite la ambigüedad de la terminología 4 . Dos rasgos resultan decisivos para comprender la noción oteriana de "montaña”:

la altura no es condición esencial de la montaña como no sea en función de la ribera

[y] por las leyes de los procesos geomórficos gallegos la montaña, de carácter siempre de casi llana, se expande en extensas llanuras curvadas (p. 171)5.

Comprobando esto en la orografía de la comarca se puede adscribir Terra de Montes al susodicho estadio del paisaje. Es este el arquetipo paisajístico más inherente al rural, lo que provoca que muchas veces los términos "montaña" y "rural" "sean usados de forma indistinta, aunque no todo el ámbito geográfico

\footnotetext{
5 "A altura non é condición esencial da montaña como non sexa en función da ribeira". "Polas leis dos procesos xeomórficos galegos a montaña, do carácter sempre de case-chan, espállase en extensas chairas curvadas".
} 
rural gallego es montaña" (González Méndez, 1995, p. 82)6 ${ }^{6}$ Este paradigma de paisaje actúa como marco en el que Viéitez insiere a sus modelos, a veces ocupando casi la totalidad del espacio de la imagen.

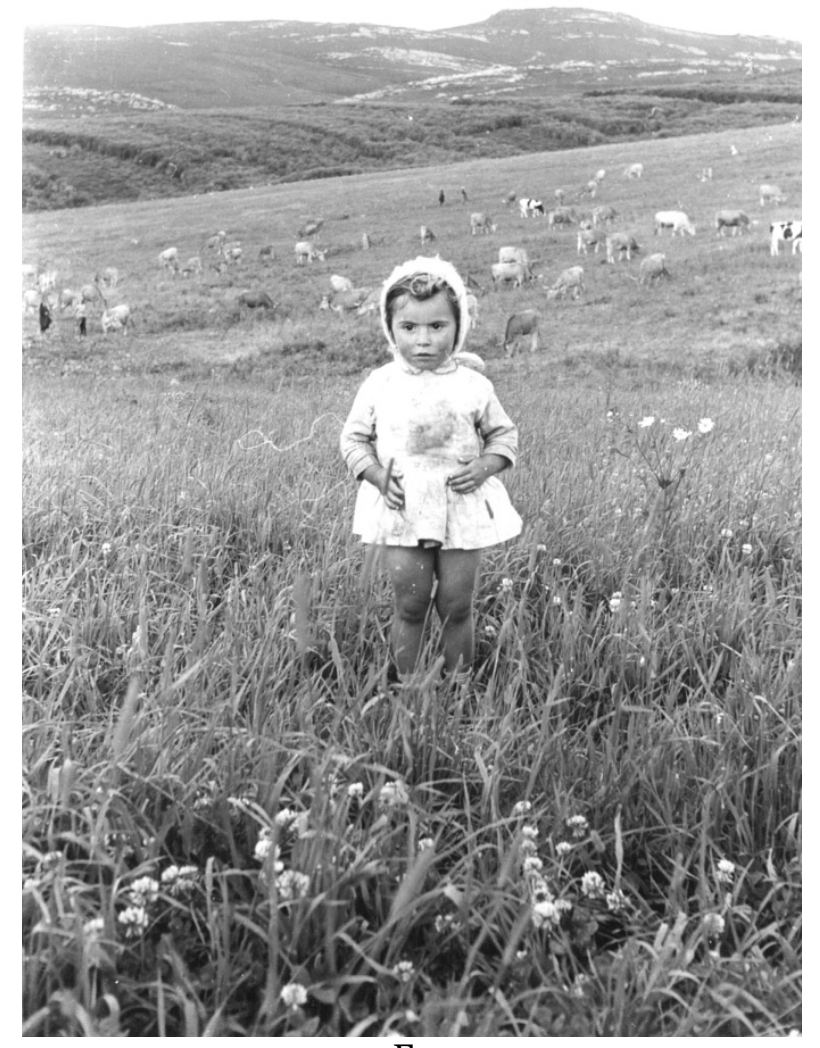

F1.

Esta decisión, común a una considerable fracción del archivo, causa ambigüedad a la hora de determinar la localización de las tomas dado que los fondos son muy parecidos, lo que en todo caso remite a una unidad paisajística común a toda la comarca.

Un componente esencial en este paisaje rural es el camino, pues sirve de nexo entre los distintos núcleos de población y el conjunto de casas que conforman un mismo núcleo, de ahí su presencia notable en el archivo Viéitez. Además, es el elemento en el que mejor se discierne el barniz semi-urbano que puede adquirir en ocasiones este paisaje. Se trata de la dicotomía "aldea / villa”, resuelta por Otero Pedrayo de esta manera: "La villa tiene un aspecto urbano que no tiene la

6 "Sexan usados de forma indistinta aínda que non todo o ámbito xeógrafico rural Galego é montaña”. 
aldea; también en esta hay cierta ordenación, pero en cuanto aparecen las aceras o las famosas acacias de bola, ya tenemos la villa” (1922, p. 45)7.

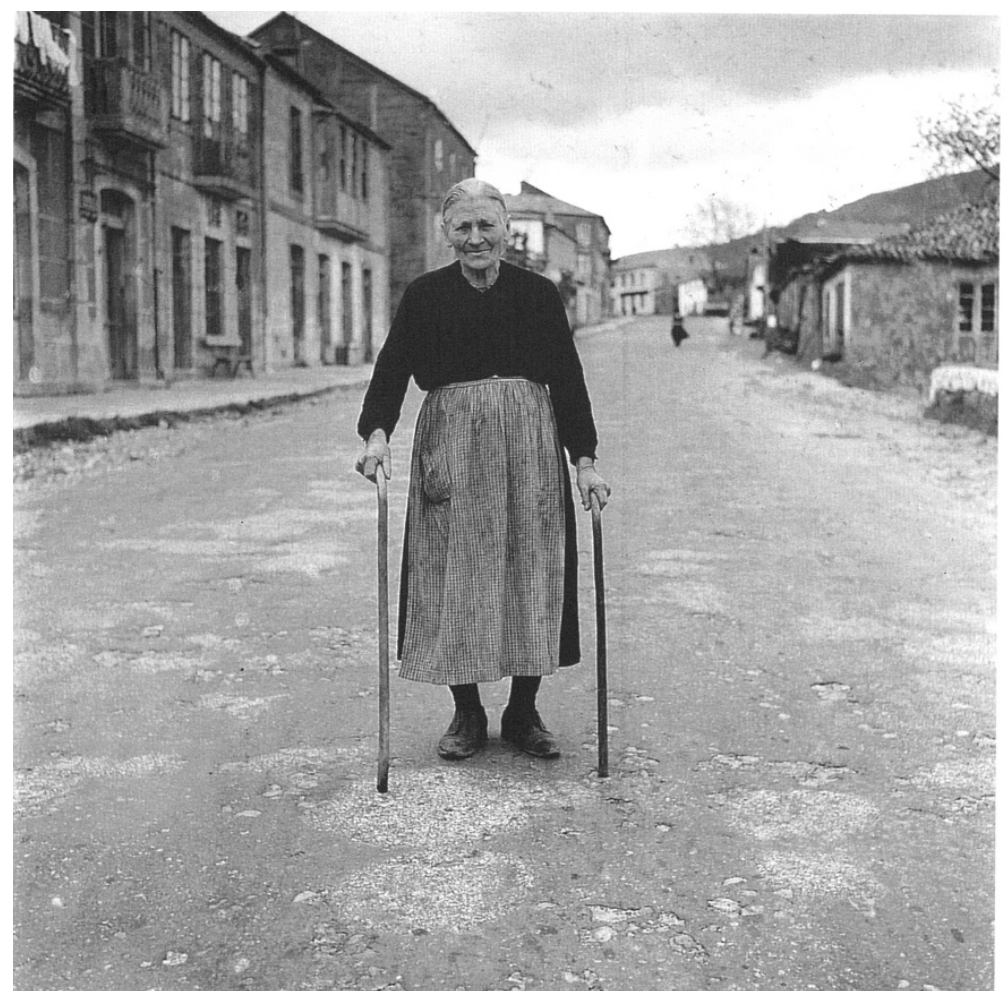

F2. Manuela Antelo, Cerdedo, 1959-1960.

Esta imagen muestra que Cerdedo se encuentra a medio "camino" entre la "aldea" y la "vila" en ese tiempo, puesto que la acera está presente solo a un lateral de la carretera.

La decisión capital de Viéitez como artista y la que fomenta que la naturaleza juegue un papel fundamental en su obra es la de salir al exterior. Las complicaciones técnicas y limitaciones creativas que encierra el estudio y la condición obligada de itinerante de un fotógrafo en su tiempo hacen surgir la necesidad de aprovechar el espacio natural. La relación que se instaura entre el humano fotografiado y la vegetación que lo rodea permite aplicar tres órdenes de espacio dentro de la clasificación de Fitter (1995). En primer lugar el managerial, que consiste en "la vinculación a la naturaleza por el desarrollo de la agricultura, en la que el humano no se limita a ser un mero participante sino un diseñador intencional del paisaje" (p. 51) ${ }^{8}$, que conecta directamente con el trabajo agrario

\footnotetext{
7 "A vila ten un aspecto urbano que non ten a aldea; tamén nesta hai certa ordenación, mais en canto aparecen as aceras ou as famosas acacias de bóla, xa temos a vila".

8 "Relation to nature with the development of agriculture, wherein humanity is no longer merely participant in but deliberative designer of landscape".
} 
que sustentaba la economía del rural gallego en esa época. En segundo lugar el possessive, que es el "impulso que celebra la patria y la propiedad" (p. 51) ${ }^{9}$, en tanto que se resalta la propiedad de la tierra como contador de riquezas para establecer comparaciones entre los vecinos. Por último, y el más destacable de los tres, producto de los otros, el quotidian, que se resume en una "reveladora actividad rutinaria y una experiencia típica, ocupacional y entretenida" (p. 52) ${ }^{10}$ que supone que "las apariencias circunstanciales son contempladas con pleno derecho" (p. 36) ${ }^{11}$ dado que ese espacio es el hábitat natural de los retratados, su forma de vida, lo que los inscribe en un vínculo básico, primitivo y perenne con la naturaleza. Resulta dificultoso adscribir una única etiqueta a cada fotografía, puesto que los tres órdenes se aprecian imbricados en el archivo. Sirva de ejemplo esta instantánea:

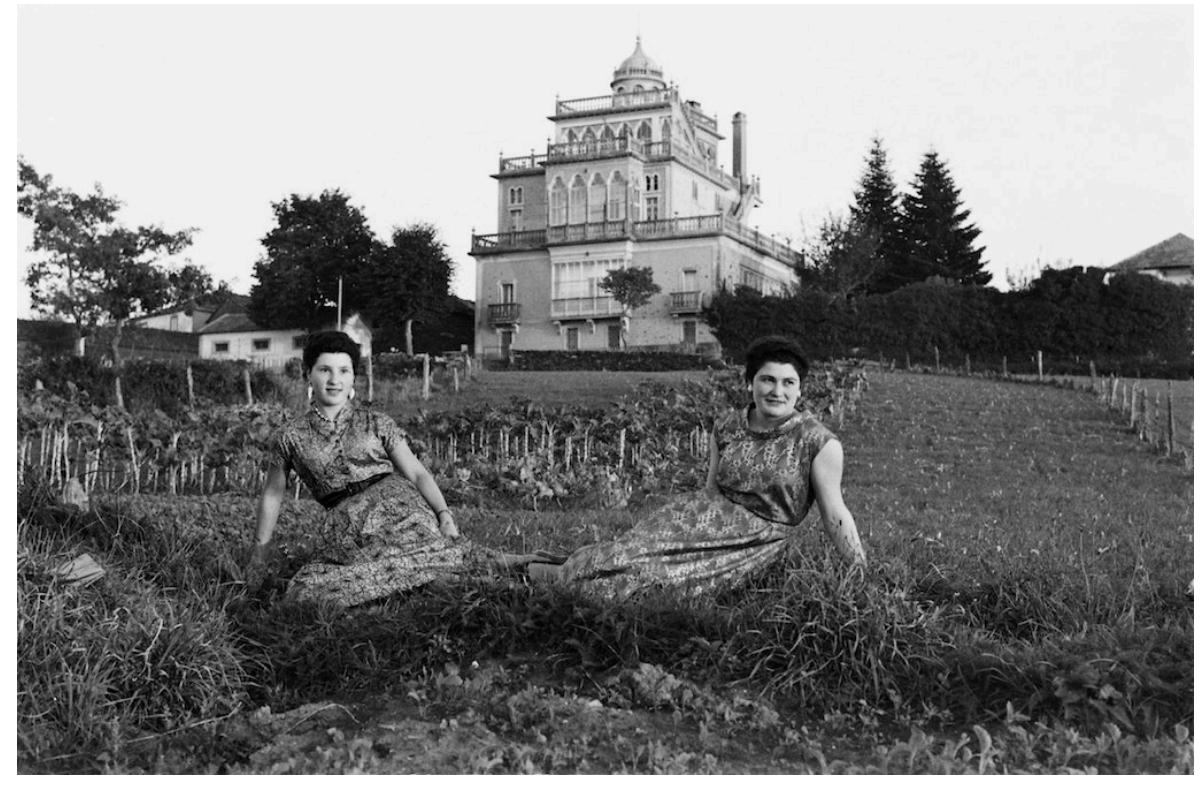

F3. Soutelo de Montes, 1955-1957.

Las dos mujeres, seguramente dueñas de la tierra, se colocan encima de ella presumiendo de su posesión (possessive), formando ellas mismas parte del paisaje (quotidian), en sintonía con ese fondo en el que destaca la huerta detrás, que funciona como una especie de metonimia del trabajo agrario (managerial) y el lujoso palacete hábilmente situado en pleno centro (possessive de nuevo). Y si el humano es parte de la naturaleza, el animal "basta para sugerir la tónica del

\footnotetext{
9 "Impulse that celebrates a homeland and ownership".

10 "Illustrating routine activity and typical experience, occupational and recreative".

11 "Contingent appearances are contemplated with pleasure in their own right".
} 
paisaje y todos los demás caracteres que en el discurrir universal lo integran” (Otero Pedrayo, 1932, p. 162) ${ }^{12}$. Valga como ejemplo de nuevo F1, en la que la abundancia de vacas es indicadora del tipo de vegetación, o cualquiera de las que ilustran el siguiente apartado.

\section{2. Los animales}

La elevada cantidad de animales que exhibe el archivo Viéitez refleja la diversidad de especies que podían ser consideradas animales domésticos, en una concepción preindustrial del término basada en el provecho que el humano puede extraer del animal. En palabras de Berger (1980, p. 14)13: “Antaño, las familias de toda clase mantenían animales domésticos porque servían a un propósito provechoso [...] La práctica de tener animales, en concreto mascotas, independientemente de su utilidad es una innovación moderna”. Se pueden agrupar en dos sencillos conjuntos que propongo denominar "animales de casa" y "animales de corte". Por supuesto, dependiendo de la especie, los límites entre ambos grupos pueden resultar borrosos.

Los animales de casa comparten el espacio cotidiano con las personas de la casa, que establecen con ellos una relación horizontal en la que tienen cabida vínculos afectivos. Con todo, conviene desechar enseguida la noción de "mascota", puesto que estos animales no poseen ninguna de las características que Berger les atribuye a las mascotas, que son estar "esterilizados o aislados sexualmente, extremadamente limitados en ejercicio, privados de casi cualquier contacto animal y alimentados con comidas artificiales" (p. 14) ${ }^{14}$; sino que gozan del estatus de miembro de la unidad familiar. Los animales que tradicionalmente son adscritos a este grupo son los perros y los gatos. La particularidad de la presencia de estos animales en las fotografías de Viéitez es que son tratados como una persona más, de ahí que sean retratados en las fotos familiares ocupando la posición que le correspondería a un hijo más.

\footnotetext{
12 "Abonda pra suxerir a tónica da paisaxe e tolo-os máis caraiteres que no decorrer universal o enteiran".

${ }_{13}$ "In the past, families of all classes kept domestic animals because they served a useful purpose [...] The practice of keeping animals regardless of their usefulness, the keeping, exactly, of pets [...] is a modern innovation".

14 either sterilised or sexually isolated, extremely limited in its exercise, deprived of almost all other animal contact and fed with artificial foods".
} 


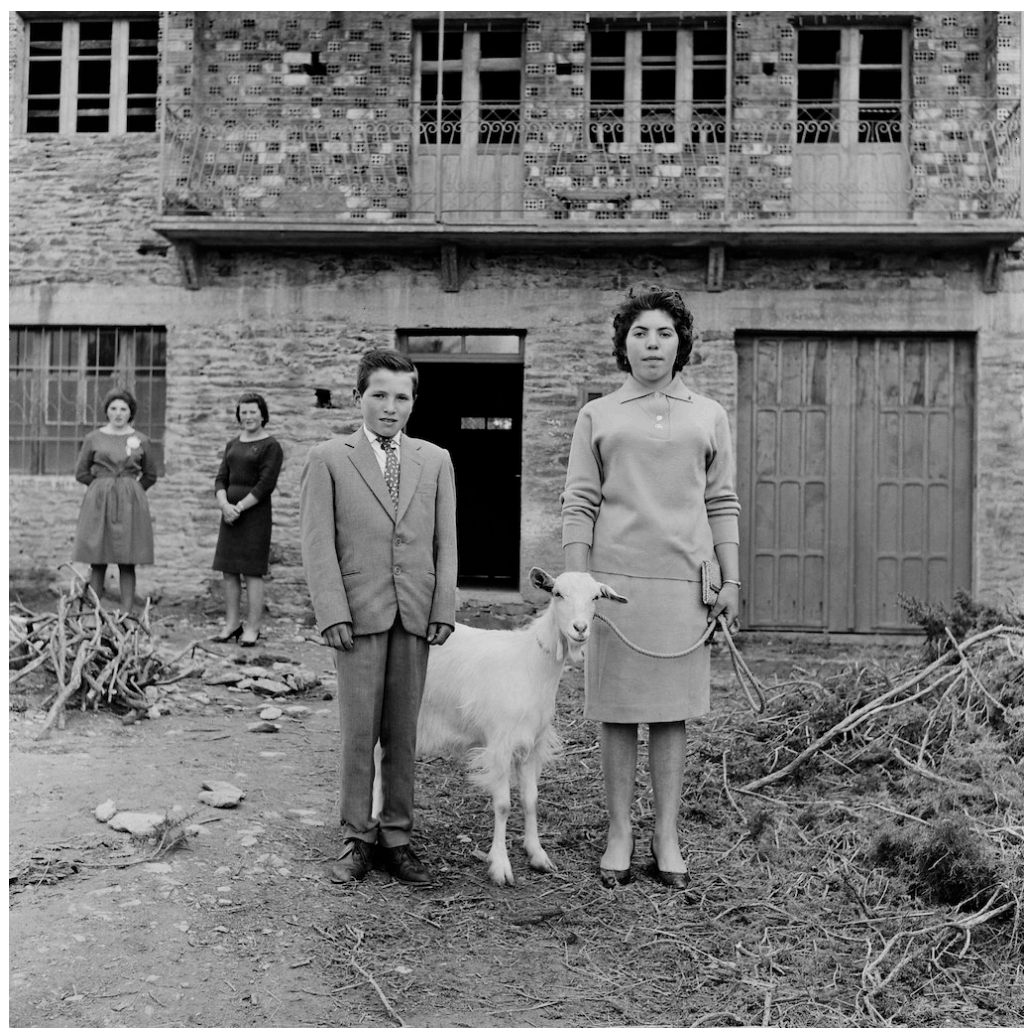

F4. San Marcos, 1962.

El rol de miembro animal de la familia es ejercido en esta fotografía por una cabra en el medio de dos hermanos, tan acicalada para la fotografía como ellos, a juzgar por su color blanco inmaculado que contrasta con cualquier otro detalle de la instantánea, de forma que se subraya "la asimilación del animal como parte de la tribu" (Lucas, 2010, p. 43). La intención de Viéitez en este tipo de imágenes no podía ser otra que retratar al animal con la misma dignidad con la que intentaba representar al humano, pero esta aplicación de ese concepto causa que al animal se le adjudique una dignidad humana, siendo así en cierta medida antropomorfizado, forzado a "parecerse al humano" y privado de sus trazos más animales.

Los animales de corte viven en un espacio separado de la casa, pero anexo a esta, asociado a alguna actividad agropecuaria. El humano establece con ellos una relación vertical que los limita a ser una herramienta más de trabajo. La especie que más representación tiene en este grupo es la vaca, foco de F1 y de esta otra imagen: 


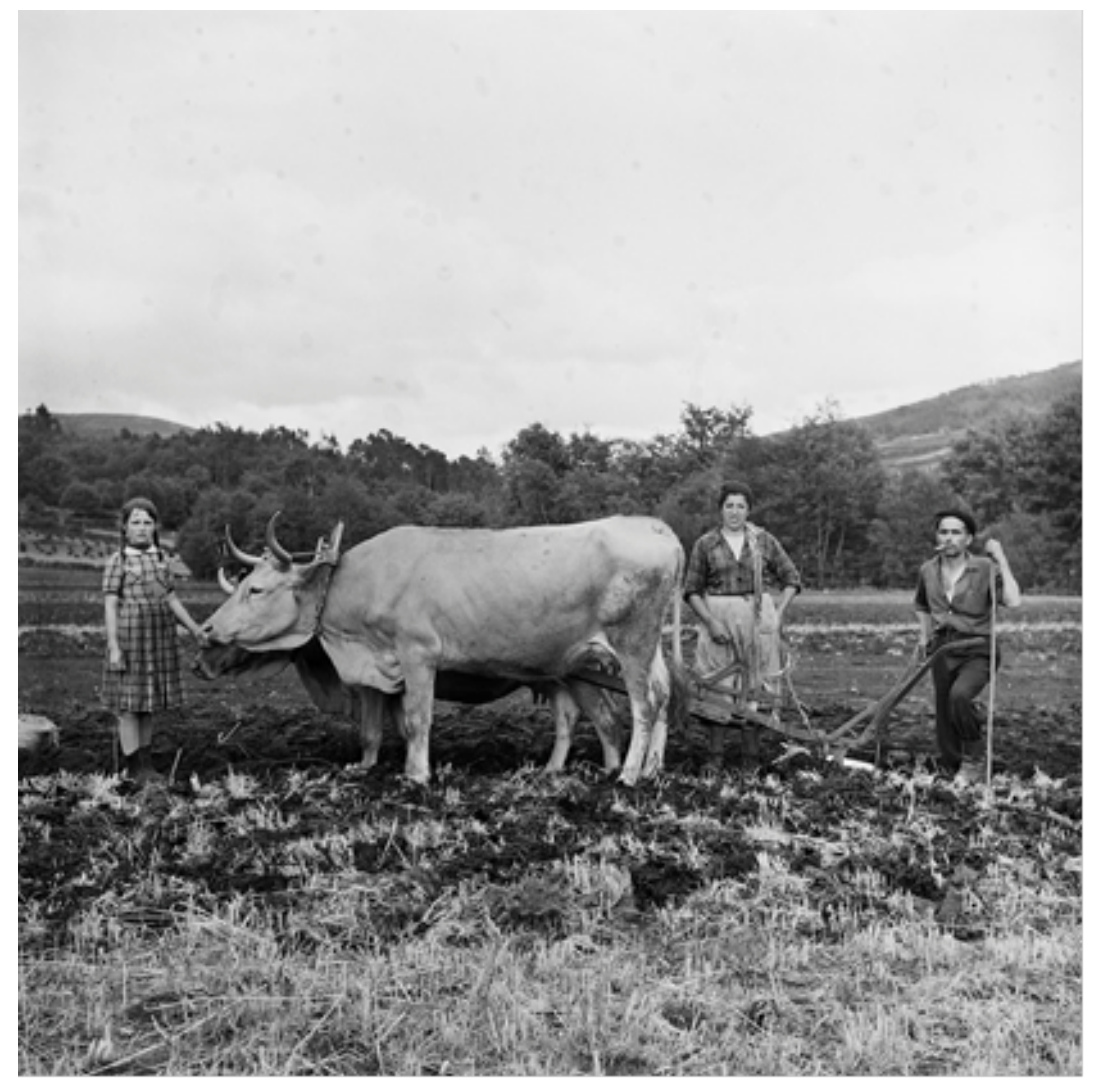

F5. Cerdedo, 1958.

Se suscribe así la afirmación de Otero Pedrayo (1932, p. 161)15 "la Galicia verdaderamente labriega se gobierna con el ganado vacuno" $\mathrm{y}$, por otra parte, se contradice esta otra: "los animales ambulan. Y como en el paisaje se busca un fondo quieto, los animales solo figuran como elemento adjetivo, pasajero" (p. 159) ${ }^{16}$, pues en estas fotografías el estatismo pretendido es lo que precisamente otorga al animal el rango de elemento nuclear de la imagen en tanto que su tamaño queda amplificado por la contraposición con la pequeñez de las niñas que aparecen en las dos imágenes traídas a colación. Otro animal de corte fundamental en el rural gallego es el cerdo, hasta el extremo de que se puede entender "como animal totémico" y, por consiguiente, "la gallega es una cultura de la cerdofilia" (Acuña Trabazo \& Gestido de la Torre, 2009, p. 134)17 en virtud de la practicadísima tradición de la matanza, definida de esta forma:

La matanza es una manifestación cultural y social de un modo de vivir propio del medio rural. Esta actividad tradicional: a) asegura un año entero de alimento

15 "A Galicia verdadeiramente labrega gobernase co gado vacuno".

16 "Os animaes ambulan. E coma na paisaxe procurase un fondo quieto, os animaes solo figuran como elemento adxectivo, pasaxeiro".

17 "A galega é unha cultura da porcofilia". 
variado, b) atañe a la unidad familiar y al grupo, pues pone en marcha un sistema de ayuda mutua, y c) predispone a la fiesta, a la celebración (p. 134) ${ }^{18}$.

Es necesario tener en cuenta estas tres funciones de la práctica a la hora de considerar el dilema ético que origina, dado que la matanza, en primer lugar, era una necesidad, así que la posible objeción moral deberá estar orientada hacia el medio que se empleaba para el sacrificio, que como revela esta imagen solía ser un cuchillo.

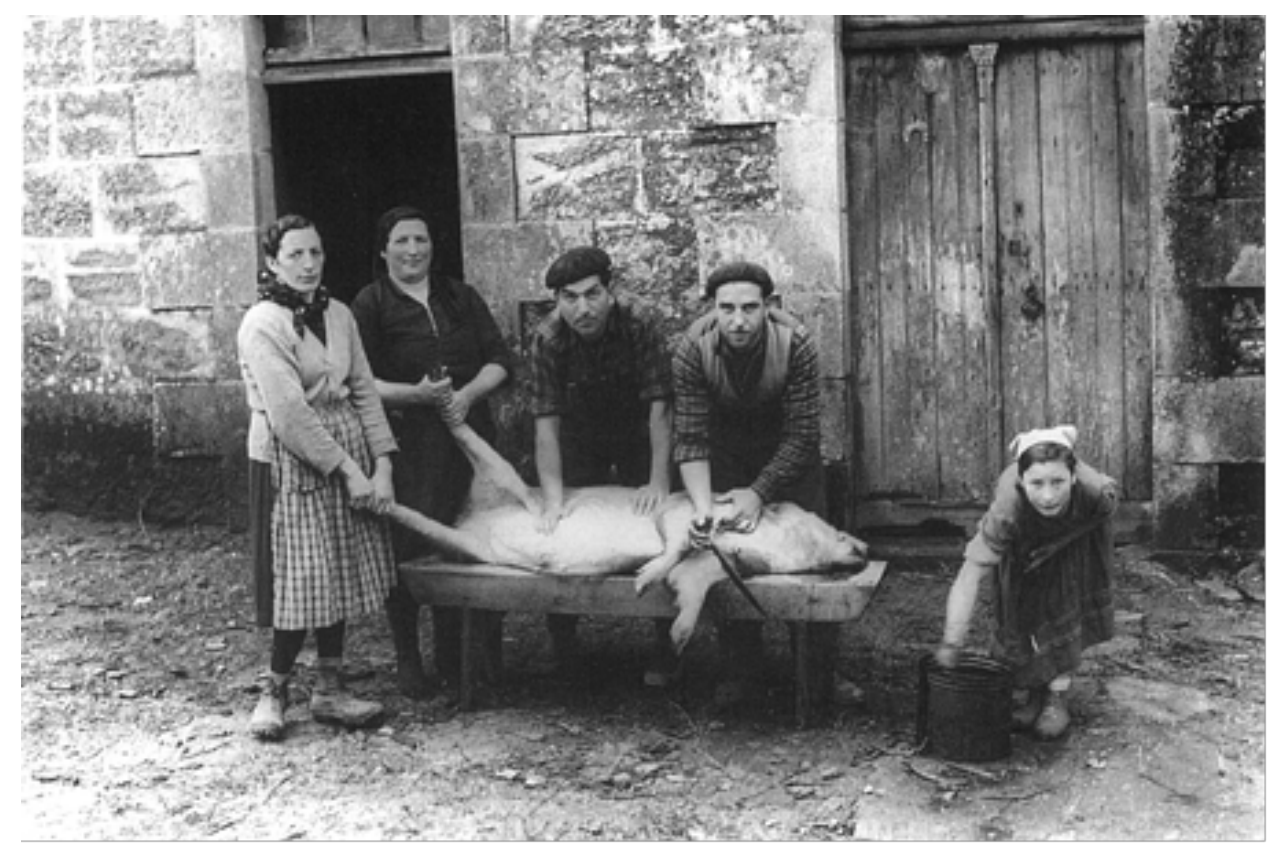

F6.

Esto invalida defensas fervorosas de esa "porcofilia" gallega como esta: "el amor a los cerdos proporciona una perspectiva más amplia de la comunión entre hombres y animales (más que la del hindú y la vaca)" (p. 134) ${ }^{19}$, refutable con el mero dato de que los hindús no matan vacas.

Por otra banda, los animales salvajes apenas aparecen en el archivo debido a su poca interferencia en el día a día del rural, empero, la caza de lobos sí era una actividad relativamente frecuente, y cuando su consecución era exitosa se solía

\footnotetext{
18 "A matanza é unha manifestación cultural e social dun modo de vivir propio do medio rural. Esta actividade tradicional: a) asegura un ano enteiro de alimento variado, b) atinxe á unidade familiar e ó grupo, pois pon en marcha un sistema de axuda mutua, e c) predispón á festa, á celebración".

19 "O amor ós porcos proporciona unha perspectiva máis ampla da comuñón entre homes e bestas (máis cá do hindú e a vaca)”.
} 
conmemorar la batida con una fotografía a modo de monumento de propaganda, con los cuerpos de los lobos muertos expuestos como trofeos.

Por último, en esta imagen se ve a un niño montado en un juguete que representa de un modo verosímil un caballo, lo cual es relevante porque "algunos de los juguetes más tempranos (cuando los juguetes eran desconocidos a la gran mayoría de la población) eran animales” (Berger, 1980, p. 22)20 y también porque, en el contexto del rural gallego, este fenómeno es indicativo de una relación especial humano-animal que reflejan todas las imágenes de esta sección, basada en la "aceptación del dualismo en el propio origen de la relación entre el hombre y el animal” (p. 28) 21.

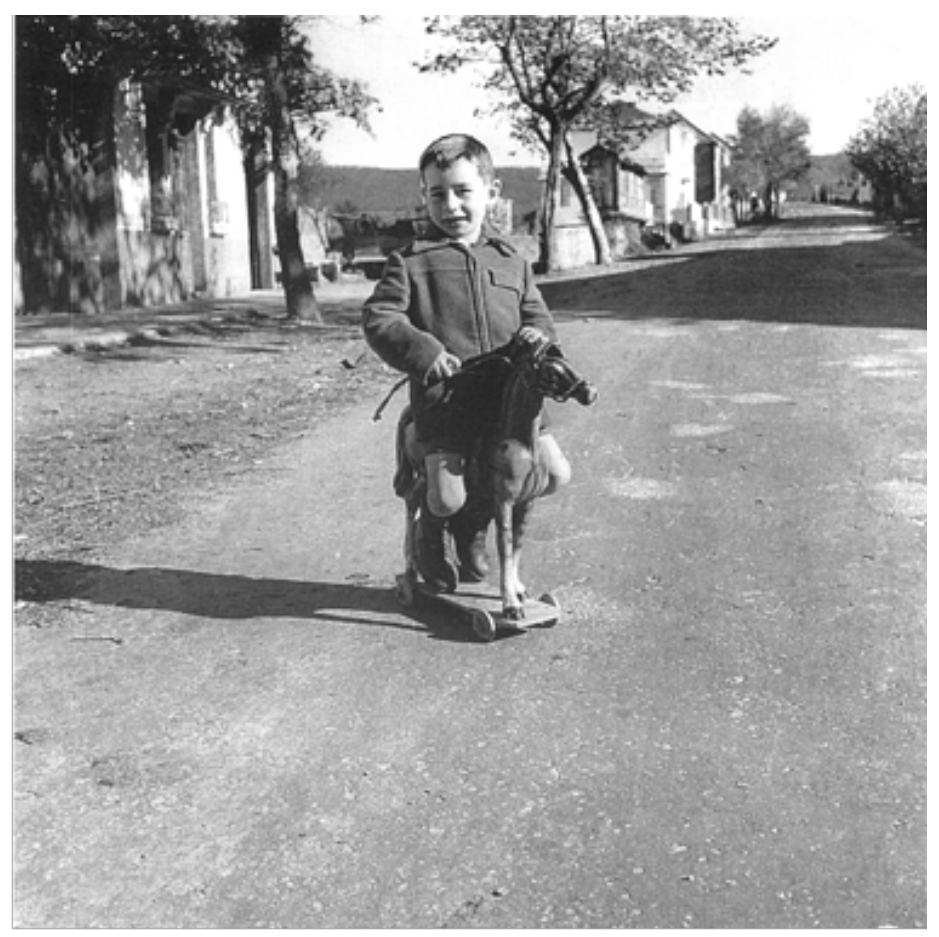

F7.

Ahora bien, al confrontar esa imagen con otras del archivo posteriores cronológicamente, se observa que el lugar del animal es ocupado por la tecnología (juguetes como aviones, coches, etc.), símil de lo que sucedería en los trabajos agropecuarios, reflejo del cambio en esa relación humano-animal que conduce hacia una marginación del animal y, en última instancia, del campesino. En palabras de Berger:

20 "Some of the earliest toys (when toys were unknown to the vast majority of the population) were animal".

${ }_{21}$ "Acceptance of the dualism at the very origin of the relation between man and animal". 
La marginación de los animales está derivando hoy en la de la única clase que, a lo largo de la historia, ha permanecido siempre vinculada a ellos y ha mantenido la sabiduría que acompaña a ese vínculo: el campesino (p. 28) 22 .

Esta implicación y sus consecuencias serán objeto de estudio en el siguiente apartado.

\section{3. El rural}

La autoimagen del rural gallego que transmite la obra de Viéitez se fundamenta en la dignidad de los sujetos retratados. Un recurso muy rentable para conseguir esa estimación es la construcción del momento. Viéitez actúa como un director de escena para organizar el tableau vivant que previamente tiene pensado. Así, en las personas que fotografía se aprecia un estatismo intencionado, la mirada dirigida a cámara y una rigidez vertical que "lleva implícita una gran dignidad en el tratamiento de las personas que nos resulta alejada del pintoresquismo con el que se suele tratar el mundo labriego" (Sendón, 2000, p. 24)23. La imagen de los labriegos con las vacas, antes aludida, sirve de prueba de este procedimiento, cuyo propósito es sugerir los duros trabajos agrarios inherentes al rural sin retratarlos en su crudeza, con lo cual el campesino en el archivo Viéitez nunca es campesino, es modelo. Teniendo esto en cuenta, no hace falta justificar la presencia de otras imágenes que, al contrario, representan el solaz, la romería, la merecida celebración después de la faena, ambientada, como no podía ser de otro modo, en un entorno natural.

Esa visión enaltecedora de un pueblo responde a la voluntad de ocultación de la miseria real que se vivía en un sistema económico "definido por una agricultura de subsistencia, basada en el policultivo y la ganadería y donde la producción para el mercado capitalista era marginal” (González Méndez, 1995, p. 81)²4. Según Gondar Portasany (2000, p. 46) lo que se procura es "hacer creer que se forma parte de una Arcadia feliz"25. El uso del término "Arcadia”, aparte de sugerir una

\footnotetext{
22 The marginalisation of animals is today being followed by the marginalisation and disposal of the only class who, throughout history, has remained familiar with animals and maintained the wisdom which accompanies that familiarity: the middle and small peasant”.

23 "Leva implícita unha gran dignidade no tratamento das persoas que nos resulta afastada do pintoresquismo con que se acostuma tratar o mundo labrego".

24 "Definido por unha agricultura de subsistencia, baseada no policultivo e na gandeiría e onde a producción para o mercado capitalista era marxinal".

25 "Facer crer que se forma parte dunha Arcadia feliz".
} 
azarosa conexión entre el nombre del fotógrafo y el del autor clásico, demuestra que el binomio rural-naturaleza es indisoluble.

Un cotejo cronológico del archivo Viéitez permite ver el proceso de modernización que experimentó el rural gallego desde los años 70 y en el que sigue inmerso. El elemento más antiguo que irrumpió en ese mundo anunciando un cambio fue el "haiga" (coche), que se percibe en las fotografías en las que aparece como un cuerpo ajeno, falsamente integrado en el paisaje rural como si fuese un componente natural de él.

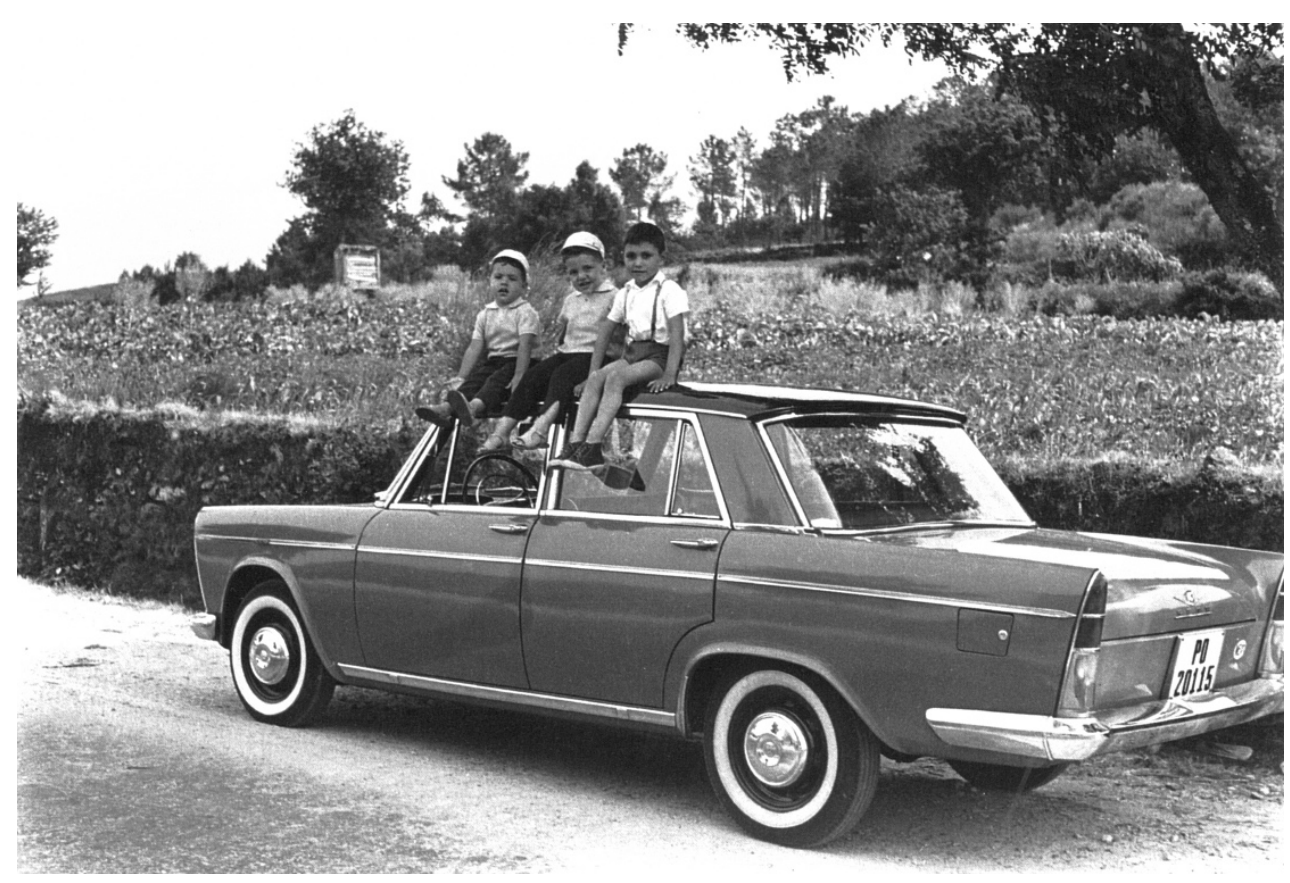

F8. Curmáns de México, Soutelo de Montes, 1962.

Aquí el coche funciona como antes lo hacía un muro de piedra: como contención para la vegetación de detrás y asiento para los niños.

A medida que avanzamos en el tiempo, encontramos más indicadores de este cambio que afecta a todas las esferas del mundo rural. Desde la oposición de los juguetes del animal y los vehículos antes comentada hasta la "desaparición del cerdo como elemento básico en la alimentación" (Acuña Trabazo \& Gestido de la Torre, 2009, p. 152) ${ }^{26}$, pasando por imágenes que rompen con las concepciones de paisaje y trabajo mantenidas hasta ahora por estar impregnadas de unos aires de modernidad que ya poco tienen que ver con la solemnidad y el modo de vida que traslucen las fotografías tomadas en el periodo 1955-1965, como son todas

26 "Desaparición do porco como elemento básico na alimentación”. 
las mostradas a lo largo de este trabajo. Más tarde llegará el paso al color, que supone un definitivo punto de no retorno; a partir de ese instante, "la naturaleza tiende a ser sustituida por los interiores" (Sendón, 2013, en "Diamante Virxilio")27, los animales dejan de tener protagonismo, el paisaje aparece modificado por factores humanos y, en conclusión, la imagen del rural que irradia ese fragmento del archivo es la de un pueblo que ha olvidado su pasado, infectado por el ambiente urbano.

\section{Conclusiones: la "colonización urbana"}

Esta mirada retrospectiva al rural de la segunda mitad del siglo XX a través de la obra de Viéitez demuestra que el maridaje naturaleza-rural en Galicia es íntimo. Como dijo Otero Pedrayo, "vivir por alentar el hombre más cerca de los ritmos de la naturaleza” (1955, p. 176)28. Más allá de algunas consideraciones de índole moral que se podrían objetar en lo que concierne al tratamiento de algunas especies animales, la principal conclusión que se infiere de este análisis del papel de la naturaleza en el archivo Viéitez es la constatación del "rápido y continuado proceso de cambio que no acaba” (García González, 2008, p. 21)²9 en que está sumido el rural gallego. La dirección y el impulso que debe tomar ese cambio es la esencia de la multitud de propuestas que se están debatiendo desde que Viéitez reprodujese con su cámara la realidad de Terra de Montes. El examen de sus instantáneas más recientes sirve como soporte gráfico del discurso que denuncia el proceso de "colonización urbana" que padece el ámbito rural, defendido por muchos escritores y teóricos de la comunidad que no solo consiguen caracterizar y visibilizar la situación imperante en las aldeas, sino que además proponen varias vías de desarrollo para poner en práctica. Destacan, por su tono vindicativo y la concreción de sus propuestas, los artículos de Roberto García González ${ }^{30}$ y Manuel Regal Ledo3¹, pero es quizá Matilde González Méndez quien mediante su denuncia expresa de forma más transparente el contenido del concepto

\footnotetext{
27 "A natureza tende a ser substituída polos interiores".

28 "Vivir polo alentar o home máis preto dos ritmos da natureza".

29 "Rápido e continuado proceso de cambio que non remata".

$3^{\circ}$ García González, R. (2008). O rural galego: retos e oportunidades cara ó século XXI. Claridade: revista da Fundación Luís Tilve, 5, 21-27.

${ }^{31}$ Regal Ledo, M. (1983). O mundo rural galego e os seus condicionamentos. Encrucillada, 34, 518.
} 
"colonización urbana": "estas propuestas de futuro en torno al medio rural están siendo vertidas desde un contexto urbano, pensadas por la población urbana y en cierta medida para solventar algunas de las necesidades de la población urbana" $(1995, \text { p.84) })^{32}$.

En este sentido el archivo Viéitez es la contrapartida artística de este activismo ruralista, que debe ser abordado teóricamente, junto con las demás manifestaciones culturales de esta ideología, por los estudios ecocríticos, con el fin de conformar un paradigma de los estudios rurales en Galicia, que bien podría adoptar como divisa la aseveración de Otero Pedrayo (1922, p. 57)33 "solo en el cultivo de la gente del campo está la formación de una Galicia como la que deseamos todos sus hijos verdaderos". Únicamente de este modo podrán aflorar vías de desarrollo capaces de preservar el futuro de una de las piezas clave en la configuración de la identidad gallega.

\section{Referencias bibliográficas}

Acuña Trabazo, A. \& Gestido de la Torre, E. (2009). A matanza: aproximación etnográfica e comunicativa. En G. Rei-Doval (Ed.), A lingüística galega desde alén mar (pp. 133-155). Santiago de Compostela: Universidade de Santiago de Compostela.

Aguilera Aranaz, M., Carabias Álvaro, A., Ledo Arias, A., Urrutia Baliño, M. \& Verdial Garay, P. (2011). Virxilio Vieitez. Vigo: Fundación MARCO, Fundación Telefónica.

Berger, J. (1980). Why Look at Animals. En About Looking (pp. 3-28). Nueva York: Vintage International.

Fitter, C. (1995). Poetry, space, landscape: toward a new theory. Cambridge: Cambridge University Press.

Glotfelty, C. (1996). Los estudios literarios en la era de la crisis medioambiental (trad. Villanueva Romero, D.). En J. Barella Vigal, C. Flys Junquera \& J. M. Marrero Henríquez (Eds.), Ecocríticas: literatura y medio ambiente (pp. 49-65). Madrid: Iberoamericana Vervuet.

Gondar Portasany, M. (2000). Virxilio Vieitez ou a realidade en traxe de domingo: unha lectura antropolóxica. En J. Fontcuberta (Ed.), Virxilio Viéitez: o retrato (pp. 33-49). Vigo: Grupo de Investigacións Fotográficas, Universidade de Vigo.

\footnotetext{
32 "Estas propostas de futuro en torno ó medio rural están sendo vertidas desde un contexto urbán, pensadas pola poboación urbán e en certa medida para solventar algunhas das necesidades da poboación urbán".

33 "Só no cultivo da xente do campo está a formación dunha Galicia como a que desexamos todos os verdadeiros fillos dela".
} 
González Méndez, M. (1995). A montaña e a aldea galega: carencias e desenvolvemento. FEGAMP: revista da Federación Galega de Municipios $e$ Provincias, 9, 81-84.

Lucas, A. (2010). La revelación de lo inmóvil. Formas de orbitar alrededor de Virxilio Vieitez. En M. Aguilera Aranaz et al. (Eds.), Virxilio Vieitez (pp. 37-48). Vigo: Fundación MARCO, Fundación Telefónica.

Sendón, M. (2000). Análise da obra de Virxilio Vieitez no período 1955-65. En J. Fontcuberta (Ed.), Virxilio Viéitez: o retrato (pp. 11-31). Vigo: Grupo de Investigacións Fotográficas, Universidade de Vigo.

Sendón, $\quad$ M. $\quad$ (2013). $\quad$ Diamante Virxilio. https://manuelsendon.wordpress.com/textos/virxilio-vieitez/diamantevirxilio-retratos-da-maxia-cotia-faro-da-cultura-2013/

Sendón, M. \& Suárez Canal, X. L. (1998). Virxilio Vieitez. Vigo: Centro de Estudos Fotográficos.

Otero Pedrayo, R. (1922). Encol da aldeia. En M. Cuquejo (Ed.), Sereno e grave gozo: ensaios sobre a paisaxe (pp. 36-57). Vigo: Galaxia, 1999.

Otero Pedrayo, R. (1932). Encol do elemento animal na paisaxe. Nós, 105, 158162.

Otero Pedrayo, R. (1955). Ensaio sobor da paisaxe galega. En M. Cuquejo (Ed.), Sereno e grave gozo: ensaios sobre a paisaxe (pp. 114-177). Vigo: Galaxia, 1999.

Terré, L. (2008). Virxilio Vieitez: un archivo rural. Madrid: La Fábrica.

Willoquet-Maricondi, P. (2010). Introduction: from Literary to Cinematic Ecocriticism. En Framing the World: Explorations in Ecocriticism and Film (pp. 1-24). Charlottesville: University of Virginia Press.

Nota del autor: un sincero agradecimiento para Keta Viéitez, hija de Virxilio Viéitez, por la ayuda prestada en la realización de este trabajo, facilitando algunas de las fotografías y esclareciendo varios aspectos de la labor de su padre, además del merecidísimo reconocimiento que debería recibir por la laboriosa e impagable tarea de organización, conservación y difusión del archivo Viéitez. 